rev.relac.int.estrateg.segur.6(2):139-161,2011

\title{
LA METAMORFOSIS DE LA HUMANIDAD EN LA ERA PLANETARIA Y LA EMERGENCIA DE LA ANTROPOLÍTICA*
}

\author{
Sergio Néstor Osorio García**
}

\section{RESUMEN}

Hoy tenemos que aprender a diferenciar y a distinguir, sin tener por ello que separar. En este sentido, hay dos conceptos claramente diferenciables y no por ello segregables: por un lado, el concepto de complejidad en las "ciencias de la complejidad", y por otro, el concepto de complejidad en el pensamiento complejo de Edgar Morin. Cuando Morin habla del pensamiento complejo para referirse a la complejidad, originariamente no se está refiriendo a lo que las "ciencias de la complejidad" entienden por complejidad, sino a lo que probablemente no cabe en ellas, a la condición de la humanidad en la era planetaria: a la Humana Conditio. Morin está de acuerdo con las "ciencias de la complejidad" en que tenemos que volver a pensar la realidad como una totalidad compleja, es decir, como un todo que está tejido en común, pues todo está interrelacionado, todo

* Este artículo es producto del proyecto, antropología y complejidad humana. Código: HUM467. Universidad Militar Nueva Granada.

** Bioeticista, filósofo, teólogo y educador. Magíster en Bioética y en Programación Neurolingüística, doctorando en Teología Pontificia Universidad Javeriana, Bogotá. Docente Facultad de Educación y Humanidades, Universidad Militar Nueva Granada. sergio.osorio@unimilitar.edu.co 
está profundamente "interfecundado". Pero al mismo tiempo, nos invita a pensar ese todo sin excluir de él a quien lo piensa. Por ello, el pensamiento complejo en perspectiva moriniana, busca comprender al "sujeto" que conoce complejamente e instala al "sujeto" (la humanidad) como epifenómeno de esa complejidad ${ }^{1}$. En este sentido, Morin, -como sabemos-, se autocomprende como un pensador humanista, y como pensador humanista busca unas estrategias para enfrentar los desafío de la humanidad en la era planetaria: la antropolítica y la política de civilización

Palabras clave: Complejidad, ciencias de la complejidad, pensamiento complejo, condición humana, antropolítica.

\section{ABSTRACT}

Today, we have to learn to differentiate and to distinguish, without having to separate. In this sense, there are two clearly distinguishable concepts and not because of it, segregated: on the one hand, the concept of complexity in the "sciences of the complexity", and on the other, the concept of complexity in the complex thought of Edgar Morin. When Morin speaks of the complex thought to refer to complexity, he is not originally referring to what the "sciences of the complexity" understand for complexity, but what probably does not fit in them, to the condition of humanity in the planetary era: to the Humana Conditio. Morin is in agreement with the "sciences of the complexity", that we need to rethink reality as a complex totality, that is, as a whole that is woven in common, because everything is interrelated, everything is deeply "inter-fecundated". But at the same time, he invites us to think that totality, without excluding from it the one who thinks it. Because of it, the complex thought in Morin's perspective, seeks to understand the "subject" that knows in a complex way, and installs the "subject" (humanity) as an epiphenomenon of that complexity. In this sense, Morin -as we know- sees himself as a humanist thinker and as a humanist thinker seeks strategies to face the challenges of humanity in the planetary era: anthropolitics and the politics of civilization.

1. Podríamos pensar, por ejemplo, en el artículo La relación antropo-bio-cósmica, en el que Morin hace un diseño de su antropología. Allí lo humano se religa a la physis, se religa al bios y se religa a la cultura, pero al mismo tiempo se les distingue de ellas. Allí lo fundamental es, pensar el ser humano que somos, -porque no somos otros-, pero de una manera distinta a como generalmente la hemos pensado en el mundo occidental. Podríamos también pensar, -y sobre esto volveré más adelante-, en el cambio que hace Morin para hablar de la situación del mundo actual, con el término planetarización y no con el término globalización. Esto significa que el problema fundamental de la humanidad no es la relación del hombre con los productos generados por su racionalidad científico-técnica, -que entre otras posibilitó el que el hombre se convirtiera en el centro del universo y también en el devastador y depredador más grande del universo-, sino de la ubicación del hombre en el cosmos (Método I), en la vida (Método II), y en la cultura (Método IIIVI) Lo que implica, sin lugar a dudas, una "antropología", pero no un antropocentrismo. ¿Puede haber una antropología sin antropocentrismo, occidelantocéntrico y burgués? Yo creo que sí, esa es la "antropología compleja" de Edgar Morin. 
Key words: complexity, sciences of the complexity, complex thinking, human condition, anthropolitics.

\section{RESUMO}

Hoje temos de aprender a diferenciar e a distinguir, sem que por isso tenhamos que separar. Neste sentido, existem dois conceitos claramente diferenciáveis e não por isso segregáveis: de um lado, o conceito de complexidade nas "ciências da complexidade" e, do outro, o conceito de complexidade no pensamento complexo de Edgar Morin. Quando Morin fala do pensamento complexo para se referir à complexidade, originalmente não está se referindo àquilo que as ciências do pensamento complexo entendem por complexidade, mas sim ao que provavelmente não se encaixa nelas, trata-se da condição da humanidade na era planetária: da Humana Condito. Motim concorda com as "ciências da complexidade" no referente a repensar a realidade como uma totalidade complexa, em outras palavras, como um todo que está entrelaçado, pois tudo está inter-relacionado, tudo está profundamente "interfecundado". Mas ao mesmo tempo, convida-nos a pensar nesse todo sem excluir dele quem o pensa. Por isso, o pensamento complexo na perspectiva moriniana procura compreender o "sujeito" que conhece complexamente e instala o "sujeito" (a humanidade) como epifenônemo dessa complexidade. Neste sentido, Morin, como já sabemos, se auto-compreende como um pensador humanista e como pensador humanista busca estratégias para enfrentar os desafios da humanidade na era planetária: a antropolítica e a política de civilização.

Palavras chave: Complexidade, ciências da complexidade, pensamento complexo, condição humana, antropolítica.

\section{INTRODUCCIÓN}

El presente artículo se desarrollará en tres partes. Una primera intentará responder a la cuestión de iqué es la complejidad para Edgar Morin?; una segunda pretenderá demostrar que la complejidad en Morin, puede ser comprendida como una metáfora para pensar la Humana Conditio en la era planetaria y, una última parte, en la que se postulará a la antropolítica como estrategia emergente para enfrentar el desafío humano en la era planetaria.

\section{1. ¿QUÉ ES LA COMPLEJIDAD PARA MORIN?}

Hemos de comenzar diciendo que se hace una inversión fundamental en el concepto de complejidad. Antes de Morin, la complejidad era sinónimo de confusión, de complicación, de oscuridad. Después de Morin, la complejidad es una categoría para poder pensar nuestra condición 
humana. Y esto desde luego implica una nueva relación con el conocimiento, o como dice este filósofo, una reforma del pensamiento, de la educación y también de la política, como se verá más adelante.

La complejidad en Morin no hace alusión a la complejidad de la que hoy nombran las llamadas "ciencias de la complejidad", sino de lo que no cabe en ellas (Morin, 2010a, pp. 81-135). Las hoy llamadas "ciencias de la complejidad", proponen una matematización compleja de la realidad, es decir, una modelización de la realidad a un nivel que era impensable para el pensamiento de la ciencia clásica. Y esto es una verdadera revolución cognoscitiva. Pero, resulta que cuando Morin habla de complejidad se refiere al estado actual de la humanidad en su proceso histórico de transformación. La situación actual de la humanidad no cabe dentro de las "ciencias de la complejidad", porque estas no se desgastan en abstracciones.

Dicho de otra manera, la complejidad en Morin no se refiere en primer lugar a los problemas actuales de las "ciencias de la complejidad", sino que más bien es una metáfora que nos lleva a complejizar esa misma complejidad, desde un pensamiento que yendo más allá de sí mismo, es decir yendo más allá de una racionalidad científico-complejizada, nos lanza a comprender la hipercomplejidad que nos constituye como humanos, que por primera vez en la historia de su auto-constitución, nos ha convertido en una comunidad de destino planetario.

La situación actual de la humanidad corresponde al final de una primera planetarización, y al inicio de una nueva forma histórica de ser, en la que los hombres y mujeres que habitamos este planeta tenemos en nuestras manos nuestra realización y/o disolución como especie. Por eso, Morin termina postulando una metáfora que nos permitirá pensarnos a la altura de nuestras nuevas condiciones: la de la metamorfosis. En este sentido, la humanidad se encuentra hoy ante la posibilidad de destrucción o de transformación hacia una nueva forma histórica de ser, que lejos de superar el antropocentrismo occidentalocéntrico, estará enraizada en sus fuentes cósmicas, biológicas y socio-culturales (Morin, 1974, pp. 15-109).

Desde este horizonte de comprensión, ¿cómo concebir la complejidad?, ¿cuáles pueden ser sus características? La complejidad puede comprenderse a partir de ciertas características: la primera de ellas es que la complejidad no sucede en el aire, sino en medio de procesos, fenómenos, circunstancias, situaciones. Una segunda es que esos procesos, fenómenos, circunstancias, situaciones están interrelacionados, es decir, no se pueden concebir sin esta condición. Una tercera característica es que esas interrelaciones no se dan de una forma externa sino interna, son dinámicas organizacionales (Morin, 1983; Solana, 2001, pp. 165-304)²; una cuarta es que en esas dinámicas organizacionales las interrelaciones no son tenues e intermitentes, sino permanentes, de lo que se puede deducir que son las relaciones las que constituyen los procesos,

2. El término organización es quizá el término central en la propuesta Moriniana. 
los fenómenos y/o las situaciones; y una quinta característica, que Morin resalta muy enérgicamente, es que esa forma de interretroacción, que es sostenible en el tiempo, es la que hace posible lo que Morin llama las emergencias.

¿Qué es una emergencia? Una emergencia es una cualidad que surge, -si ustedes quieren en términos funcionalistas-, de las suma de las partes, pero que no puede ni reducirse a las partes, ni quedar restringida ni explicada desde alguna de ellas. Un ejemplo muy sencillo para poder explicar esto son los hijos. Los hijos no pueden ser sin sus padres, los hijos de alguna manera son la suma de las partes (sus padres), pero, al mismo tiempo, son más que la suma de las partes (son más que sus padres), es decir, son una nueva organización que apropiando lo anterior ha generado unas características cualitativamente distintas de lo anterior, se ha transformado en un nuevo ser. Este modo de ser depende profundamente de lo anterior, pero dependiendo de lo anterior para ser, ya no es lo anterior porque es otra cosa: eso es una emergencia.

Para poder pensar las nuevas formas organizacionales, las emergencias no nos sirven ni como categorías, ni conceptos, ni las lógicas que podían explicar la realidad en su organización previa. Dicho desde el ejemplo anterior, no podemos explicar al hijo desde el padre, no puedo explicar el hijo desde la madre o desde las suma de ambos. Pero, tampoco puedo explicarlo al margen de ellos. Pensar religando, y al mismo tiempo distinguiendo, es lo que Morin llama pensamiento complejo. Un pensamiento capaz de comprender la complejidad que somos, y de la que al mismo tiempo hacemos parte. La complejidad es entonces, como veremos más adelante, una metáfora que nos invita a pensar las cualidades emergentes de la Humana Conditio en la era planetaria.

En síntesis, la complejidad Moriniana no se refiere originariamente a ninguno de los problemas centrales a partir de los cuales trabajan las "ciencias de la complejidad", sino más bien a una metáfora que nos lleva a complejizar el pensamiento de la complejidad, para comprender la hipercomplejidad que somos y nos constituye en tanto que humanos. Humanos que vivimos en un planeta ubicado en un suburbio de una galaxia, en medio de muchísimas galaxias, en un momento histórico específico de su auto-constitución como especie. De un "sujeto" que tiene entre sus manos, -por primera vez en la historia-, el destino de su propia realización y/o destrucción, y esto en un sentido planetario (Morin \& Kern, 1993, pp. 45-74).

Teniendo en cuenta lo anterior, podemos decir que la preocupación fundamental de Morin no es la inteligibilidad científica y compleja de muchos de los factores que constituyen el mundo físico, biológico y químico, sino la preocupación por pensar la hipercomplejidad humana que somos y nos constituye desde sus fuentes físico-químicas, biológicas y antropo-sociales. Aunque para ello tenga que hacer una verdadera reforma del pensamiento y de la educación, pues desde la concepción actual es imposible hacerlo. Lo que ha impedido que nos percibamos de otro modo ha sido la "comprensión" de esa complejidad que somos. Dicho de otra manera, el hombre es el único ser que puede tomar conciencia de lo que es, y esto lo une al mismo tiempo 
que lo "separa" de la complejidad en la que se constituye su propia identidad. ¿Cómo pensar la complejidad que somos y nos constituye en un momento en que las "ciencias de la complejidad" han hecho su eclosión en el mundo de las ciencias "duras"?

Morin haciendo alusión a una metáfora arquitectónica, nos dice que su pensamiento complejo se encaja y diferencia a la vez de unos conocimientos a partir de los cuales se ha construido, y al mismo tiempo se ha "separado". La metáfora arquitectónica para hablarnos del pensamiento complejo es la de una casa de tres pisos.

En el primer piso, es decir en la base, estarían las tres grandes teorías contemporáneas: la teoría de la información, la teoría cibernética y la teoría general de sistemas, que le ha permitido pensar en un principio de causalidad no lineal. En el segundo piso estarían las teorías de la autoorganización, especialmente de autores como I. Prigogine, H. Atlan, N. Wiener, Von Foster, Von Neumann. Ellos le permitieron comprender de una manera entrañable, la emergencia de toda organización, pero todavía más, le permitieron comprender cómo la organización viviente no solamente se organiza a partir de muchos componentes sino que la complejidad viviente es auto-organizada: ella misma en diálogo con el entorno crea sus propias posibilidades de subsistencia. En el tercer piso, estaría lo que él llama el pensamiento complejo, es decir la capacidad de pensar al ser humano que somos, desde las posibilidades que se han abierto desde las teorías anteriores y desde las reflexiones críticas del conocimiento que se han dado después de Husserl y Heidegger en la filosofía (Morin, 1997, pp. 13-22; Morin, 1996, pp. 202-217)3.

Todo este andamiaje se encuentra estructurado en su famosa obra de seis tomos que se llama "El Método". Pero lo que no queda suficientemente explícito en esta voluminosa obra es la apuesta fundamental de su pensamiento moriniano: la apuesta por humanidad-otra. Esto aparece de manera más transparente en sus escritos, por decirlo así menores, en los que el pensador le apuesta a la emergencia de una humanidad como comunidad destino, a una humanidad que

3. En una reflexión posterior, Morin nos dice que su gran obra El Método se ha podido realizar gracias a cuatro grandes aportaciones: "El Método integró en su seno cuarto aportaciones: -la aportación de una tradición filosófica de afrontar contradicciones que, nacida en Occidente con Heráclito, prosiguió con Nicolás de Cusa, Pascal, Hegel, Marx, Adorno, Jung, y se vio científicamente prolongad con Böhr, Gödel, Lupasco; -la aportación de las "tres teorías" (información, cibernética, sistema) y de las teorías de la auto-organización y de la autoproducción (Von Foerster, Maturana, Atlan); la reflexión filosófica sobre la naturaleza de la ciencia (Husserl, Heidegger); -la reflexión epistemológica sobre la primera revolución científica del siglo XX, suscitada por la irrupción de lo incierto (desorden, indeterminación, azar, caos) y efectuada por Bachelard, Popper, Lakatos, Kuhn, Feyerabend; añadía a ello una reflexión sobre la segunda revolución científica en curso que, al objeto de las ciencias compartimentadas, sustituye el carácter inseparable de las realidades sistémicas (ecología científica, ciencias de la tierra, cosmología)... Yo no sólo he cientifizado una gran corriente filosófica, sino que he querido que pueda ponerse de relieve un pensamiento pertinente a partir de un continuo ir y venir entre filosofía y ciencia. He intentado prolongar científicamente la filosofía y filosóficamente la ciencia. iSacrilegio! iCuántas fronteras cruzadas sin pasaporte! iCuántos santuarios profanados! iCuántos odios ineptos por una aventura de buena voluntad!" (Morin, 1996, pp. 274-275). 
por primera vez tiene entre sus manos la posibilidad de desaparecer o de continuar en la tierra en sentido planetario. De esta manera, lo que está en juego en la apuesta moriniana no es un articulado teórico-conceptual de tipo complejo, sino la humanidad actual en medio de un proceso histórico de planetarización.

En Morin, hay una crítica muy fuerte a la sociedad contemporánea, pues para él la sociedad actual es una sociedad que a pesar de sus grandes progresos, de sus grandes conocimientos, de su innegable desarrollo científico-tecnológico, sigue siendo una sociedad bárbara ${ }^{4}$ que se encuentra en su edad de hierro planetaria (Morin, 2009a), como en la prehistoria de la evolución de su espíritu (mind). La sociedad, para Morin, ha perdido su horizonte como humanidad y por tanto hay que hacer una apuesta antropolítica que posibilite la construcción de una sociedadotra, más civilizada y que posibilite al mismo tiempo la apropiación del planeta como una "tierra-patria" (Morin \& Kern, 1993).

En síntesis, la complejidad en Morin no trata de los asuntos propios de las ciencias de la complejidad, sino de un nuevo modo de organizar el pensamiento de tal manera que posibilite la emergencia de una nueva manera histórica de ser, que posibilite la transformación de la hominización en humanidad.

\section{LA COMPLEJIDAD COMO METÁFORA PARA PENSAR LA HUMANA CONDITIO EN LA ERA PLANETARIA}

El acontecimiento, el fenómeno, que a Morin le interesa pensar es la emergencia de la humanidad en la era planetaria. La planetarización no hace parte de los fenómenos trabajados dentro de las ciencias de la complejidad, no puede ser un fenómeno tratado por estas porque no se puede matematizar, así sea complejamente. Pero esto no significa que no la podamos pensar. Entonces, pensar la condición humana (Humana Conditio) en la era planetaria significa para Morin, pensar la hipercomplejidad que somos y nos constituye.

Ahora bien, como la complejidad es una emergencia no la podemos pensar desde las categorías y las lógicas (paradigmas) anteriores a dicha emergencia, de esta manera, se hace necesaria una nueva forma de pensar: un pensamiento complejo. Y con esto está ya más claro lo que busca Morin: pensar al ser humano en una era planetaria, en una época de finalización de un proceso de hominización y posiblemente de un nuevo comienzo que dará origen a la humanidad, a una planetarización ya no occidentalizada, sino por primera vez mundial: planetaria.

4. Metáfora que Morin recoge de Max Weber para quien la sociedad moderna además de ser desencantada se ha convertido en una "jaula de hierro". 
Y aquí viene un segundo punto que me gustaría dilucidar: la Humana Conditio. Esta la categoría a la que apela Morin, para pensar la hipercomplejidad que nos constituye en la era planetaria. Para ello hay que hacer una diferenciación analítica entre el término globalización y el término mundialización o planetarización.

El término planetarización es un término más complejo que globalización, porque es un término radicalmente antropológico que expresa la inmersión simbiótica, pero al mismo tiempo extraña, de la humanidad en el planeta tierra. Porque la Tierra no es sólo un terreno donde se despliega la globalización, sino una totalidad compleja físico/biológica/ antropológica. Es decir, hay que comprender la vida como emergente de la historia de la Tierra y a la humanidad como emergente de la historia de la vida terrestre. La relación del ser humano con la naturaleza y el planeta no puede concebirse de un modo reductor ni separadamente, como se desprende de la noción de globalización, porque la tierra no es la suma de elementos disyuntos: el planeta físico, más la biosfera, más la humanidad, sino que es la relación entre la tierra y la humanidad que debe concebirse como una entidad planetaria y biosférica.. Además porque el término planetarización contiene en su raíz etimológica la idea de aventura de la humanidad. Comprender esta aventura y su posible destino es el desafío principal de la educación planetaria, y en este contexto, es primordial para alcanzar una civilización planetaria (Morin, Roger \& Motta, 2003, pp. 80-81).

La globalización entonces tiene que ver con la manera como occidente, a partir de la época moderna, ha logrado mediante un proceso unilateral consolidar una cierta identidad histórica y cultural. Pero, para comprender la Humana Conditio en la era planetaria se hace necesario ubicar a la humanidad en un horizonte más amplio: el de la planetarización. La planetarización puede ser comprendida a lo largo de la obra moriniana a través de varias metáforas, aquí utilizaré algunas de ellas para mostrar la pretensiosa tarea de un pensamiento complejo al estilo moriniano como la emergencia de una antropolítica y de una política de civilización.

\section{a) La metáfora del Titanic}

Según Morin (2008) la humanidad actual es como el Titanic. ¿Hacia dónde apunta esta metáfora? A mostrar que todo el desarrollo, que el progreso, que toda la posibilidad tecno-económica de la sociedad actual, incluyendo la revolución informática contemporánea, se parece mucho a un gran Titanic, y que ese Titanic tiene cuatro grandes motores: la ciencia, la técnica, la industria y el exacerbado interés de lucro.

El primer motor es la ciencia actual compartimentada, absolutamente rota entre sus objetos y sus métodos de conocimiento, genera una nueva ceguera que jamás había vivido la humanidad. Se trata de la ceguera que genera el propio conocimiento científico. La ciencia nos da luz, 
sin duda, pero al mismo tiempo nos somete a la más grande ceguera: la del conocimiento y ¿quien le pone control a la ciencia?

El segundo motor es la técnica. Hoy podemos decir que nos encontramos en una sociedad tecno-científica en la que la ciencia hace uso de la tecnología, que a su vez hace uso de la técnica para hacer posibles experimentos o innovaciones. La técnica nos ha traído grandes adelantos, pero la técnica también ha producido un gran problema: sólo hemos pensado una dimensión de la existencia: la dimensión técnica. La dimensión de la realidad puede ser computable, cuantificable, matematizable y que puede ser conocida a través de los modelamientos que hacemos sobre ella, esta dimensión técnica no es toda la realidad. Para Morin el ser humano es prosaico al mismo tiempo que poético. Mediante la dimensión prosaica el ser humano sobrevive, se desgasta, trabaja, se hace viable. Y en eso gasta más o menos el $80 \%$ de su vida. Pero el ser humano también es poético: ama, siente, se relaciona, sufre y espera. La dimensión poética de la existencia no puede ser comprendida desde la dimensión prosaica, aunque la presupone. Sólo la dialogización entre la dimensión prosaica y la dimensión poética de la realidad nos dará una existencia completa, integral. Pero, ¿quién le pone control a la técnica?, ¿cómo pensar la dimensión no-técnica de la existencia?

El tercer motor es la industria. Hoy para nadie es extraño que nos encontramos en una sociedad industrial -aunque para algunos ya estamos en una sociedad posindustrial (Corbí, 1992, pp. 17100)-, que tiene unos enormes valores y unas enormes posibilidades, como unas enormes creaciones, pero que al mismo tiempo tiene unos enormes sinsabores: hemos mecanizado la existencia, hemos cronometrado todo, hemos tornado en producción. Hemos convertido la vida en indicadores de productividad. Pero la vida toda no cabe allí, hay algo que queda por fuera y debe ser pensado de otra manera.

El cuarto motor es el exacerbado interés de lucro, muy bien caracterizado por la economía de mercado capitalista que solamente piensa en lo que se llamaría la rentabilidad económica. Desde estos cuatro motores que jalonan la nave planetaria llamada Titanic, vamos todos, sin excepción alguna, al hundimiento, sólo que aquí no se va a hundir el Titanic, sino la humanidad entera.

La globalización para Morin es la última etapa de la era planetaria, y se corresponde con una planetarización tosca, bruta, unidimensional. Pero curiosamente esa globalización -que Morin llama mundialización tecno-económica-, fue posible en la medida que otra mundialización, la mundialización humanística le sirvió de inspiración y fundamento.

Dicho de otra manera, -y aquí Morin recoge la tesis de la escuela de Frankfurt-, estamos sometidos a una racionalidad instrumental dejada a sus propias lógicas, y como esas lógicas no tienen ningún control, entonces como el Titanic, la humanidad, terminará en el fondo del mar. La mundialización tecno-económica, en términos de Adorno, se presenta como una dialéctica negativa que ha sido posible a partir de la mundialización humanística, -que a su vez también 
fue negativa-, pues comprendió al hombre europeo como centro del universo y derivó en el extremo contrario al que buscaba. Desde esta perspectiva el carácter normativo de la modernidad: igualdad, libertad, fraternidad claudicó en el dirigismo político de corte totalitario, y en una economía de mercado dejada sus propia lógica: más dinero, más poder, más control (Habermas, 1987a, pp. 365-508; 1987b, pp. 527-572; 1989, pp. 397-433). Morin dará una nueva posibilidad al hombre, pero para ello, el hombre deberá controlar a al controlador: la mundialización tecno-económica.

\section{b) La nave bimotor o de la dialógica planetarizadora.}

Morin nos propone que nos imaginemos la situación actual de humanidad como si esta fuera una nave bimotor: un motor jalona la mundialización tecno-económica, -que dejada a su propia lógica nos llevará a la muerte-, y el otro motor jalona la mundialización humanística. Aquí está el pensamiento humanístico, la toma de conciencia de los derechos humanos, los movimientos de liberación, el arte, la poesía, la conciencia ciudadana, etc. Mundialización que ha de ser apropiada de manera crítica, pues de lo contrario podríamos recaer en un antropocentrismo occidentalocéntrico; aquí también estaría justificado el cambio de categorías: no se trata únicamente de la globalización, sino de una autentica planetarización.

Esta segunda metáfora que usa Morin para pensar la globalización de una manera menos brutal, de una manera menos tosca, de una manera menos simplificadora, hace posible la interpretación de la planetarización como un dialógica a la vez concurrente, antagonista y complementaria entre una mundialización tecno-económica y una mundialización humanística ${ }^{5}$. De la interretroacción de estos dos motores podrá emerger un proceso dialógico de planetarización que recogería lo mejor de la mundialización tecno-económica desde una mundialización humanística, que completaría el proceso del hominización con el devenir de un auténtico proceso de humanización.

\section{c) De la sociedad-imperio a la sociedad-mundo.}

Morin utiliza una tercera metáfora: el paso de la sociedad-imperio a la sociedad-mundo (Morin, 2003e; Morin, Roger \& Motta, 2003a, pp. 75-118). Con esta metáfora, Morin nos introduce en

5. Los francófonos nunca hablan de globalización, hablan de planetarización o hablan de mundialización, pero no hablan de globalización. La globalización hace alusión a una forma de concebir la humanidad más próxima a la concepción anglo-americano-israelí, por demás hegemónica en el plano político y económico actual. Visión que justificaría a la humanidad en tanto que Titanic con sus cuatro motor ciencia, técnica, industria e interés económico. En nuestro medio hablamos fundamentalmente de la globalización, es decir, de lo que produce el mundo angloamericano-israelí y ello no es ninguna coincidencia o casualidad. 
la tradición fenomenológica, pues en ella y desde ella el hombre es el único ser que tiene mundo. El mundo, fenomenológicamente hablando, no es un habitáculo en el que se encuentran las cosas y también el hombre, sino que es una manera histórica de habitar la tierra (Heidegger, 2003, pp. 115-127; 1994, pp. 127-142; Scherer, 1975, pp. 11-60) ${ }^{6}$. La sociedad en tanto que mundo, será entonces la manera como los humanos en la era planetaria se reorganizan en una nueva figura de humanidad, capaz ella de solucionar sus problemas de vida o muerte, sus posibilidades de sostenibilidad como especie en medio de los demás sistemas bióticos y nobióticos de los cuales la vida humana hace parte y depende. Nos encontramos así ante una nueva conciencia de humanidad que es a un mismo tiempo individuo-sociedad-especie (Morin, 2003).

Ello supone a la vez el desarrollo de la relación individuo-sociedad en el sentido democrático, y el desarrollo de la relación individuo-especie en el sentido de la realización de la humanidad. No tenemos las llaves que nos abran las puertas de futuro mejor, pero podemos emprender nuestras finalidades: la continuación de la hominización en humanización, vía ascenso a la ciudadanía terrestre (Morin, 2003d).

La humanidad por primera vez en su proceso de auto-constitución como especie puede advenir a una nueva figura histórica, es decir, una nueva configuración societal producto de la anterior configuración, pero improbable desde ella; una nueva configuración que no se da sin la condición anterior, pero será cualitativamente distinta de lo anterior: es una emergencia. La nueva organización emergente no está ganada, puede ser el comienzo o puede ser el fin, de nosotros dependerá el desenlace. En "Los desafíos de la educación en la era planetaria" Morin cita un texto de J. Robin en la que se refiere a esto mismo:

Los focos de cambio de era se revelarán, no lo dudemos, múltiples, inesperados, diseminados por toda superficie la Tierra, lo quiera o no, lo sepa o no, la humanidad ha entrado en su fase de mundialización y la civilización por venir, si debe haber una, no puede ser más que planetaria. Nos queda por saber cuál será el atractor: ¿̇la universalización del sistema actual, para mayor provecho de algunos o la expansión de los habitantes de la Tierra hacia la puesta en común de sus diferencias culturales? (Morin, Roger \& Motta, 2003a, p. 77)

Vivimos entonces, en una planetarización a medias.

Quiero decir que estamos llegando no sólo a un término histórico, sino a los preliminares de un nuevo comienzo, que, como todos los comienzos, conllevará barbarie y crueldad,

6. En donde Scherer presenta a Heidegger como el primer pensador ecológico de occidente. 
y que la ruta hacia una humanidad civilizada será larga y aleatoria. Y esta marcha, que ya se inició después de Hiroshima, se hará a la sombra de la muerte. Quizá este comienzo sea un fin (Morin, 2003e, p. 10).

Esta posibilidad no será un paraíso, una situación idílica que nos evite la creatividad y el compromiso de luchar, como diría Goethe, por una "altísima existencia", sino que:

Cualquiera que sea su vía de formación, la sociedad-mundo no aboliría por sí misma las explotaciones, las dominaciones, las negaciones, las desigualdades existentes. La sociedad-mundo no va a resolver ipso facto los graves problemas presentes en nuestras sociedades y en nuestro mundo, pero es la única vía por la cual, llegado el caso, podría progresar el mundo (Morin, 2003e, p. 10).

Cuando Morin entra a caracterizar este "comienzo que puede ser un fin", históricamente se ubica en los últimos cuatro (4) siglos de la planetarización, teniendo como eje la mundialización económica, y allí sostiene tres grandes tesis, estas son:

a. La mundialización tecno-económica ha sido simultáneamente la mundialización de la dominación (Para Morin la planetarización comienzo con la conquista de América);

b. La mundialización tecno-económica tiene como dinamizador un aparato cuatrimotor compuesto por la ciencia, la técnica, la industria y el interés económico desmedido, y

c. La mundialización tecno-económica es al mismo tiempo la mundialización de la guerra.

Sólo en esta época de "barbarie civilizada" (Morin, 2009a) la humanidad se ha unido en torno a aquello que inevitablemente la destruye: la guerra (Morin, 1982). Por esta razón, Morin interpreta los conflictos del siglo XIX, las guerras del siglo XX y el terrorismo del siglo

7. En este texto Morin hace un análisis muy sugestivo del ataque a las torres gemelas en New York y advierte que el ataque del 11 de septiembre mostró que tenemos una situación planetaria y una conciencia de destino planetario que a su vez genera dos posibilidades, una que la ONU piense en otras posibilidades de gobernabilidad planetaria y de policía planetaria o que los Estados Unidos le tomen la delantera y su abroguen ellos mismos, el carácter político y policial de la humanidad, con lo cual se crean la condiciones de posibilidad para el fenómeno del terrorismo mundial. El terrorismo, en este sentido, sería la forma como el sistema produce su propia exageración para poder controlarla en términos militares. En este último texto, Jean Baudrillard, desarrolla la explicación sobre la hipótesis soberana del terrorismo en la que se muestra cómo las acciones terroristas son ellas mismas expresión del sistema perverso que las produce: "La táctica del modelo terrorista consiste en provocar un exceso de realidad y en hacer que el sistema se derrumbe bajo este exceso de realidad. Toda la irrisión de la situación y, además, la violencia movilizada del poder se tornan contra éste, ya que los actos terroristas son a la vez el espejo exorbitante de su propia violencia y el modelo de una violencia simbólica que le está prohibida, de la sola violencia que el sistema no puede ejercer: la de su propia muerte" (Baudrillard, 2003, p. 28). 
XXI, no como situaciones aisladas, sino como culminación de una mundialización burda, tosca y unidimensional.

El atentado a las Torres Gemelas nos reta a pensar el paso que se podría dar desde una sociedadimperio a una sociedad-mundo. Es decir, el paso de un sistema totalitario hacia una nueva configuración planetaria en la que entren todos los habitantes de la tierra con sus diferencias culturales (Morin, Roger \& Motta, 2003a, pp. 77-118; Morin, 2003b, pp. 35-54) ${ }^{7}$. A esto le llama Morin la Confederación de la Especie Humana de cara a una sobrevivencia planetaria. Este es el desafío político de humanidad en "la edad de hierro de la era planetaria".

La humanidad como comunidad de destino planetario, se encuentra por primera vez en la historia de su auto-constitución como especie con la posibilidad de transformar su civilización occidentalizada: "sociedad-imperio" en una civilización planetaria: "sociedad-mundo", o bien ante las posibilidades de abortar su propio proceso de gestación.

Esto equivale a decir que lejos de forjarse como una sociedad-mundo civilizada, según lo habíamos considerado, se forjará, si es que se logra, una sociedad-mundo burda y bárbara. Más aún, frente a la posibilidad de una sociedad-mundo confederal, está la posibilidad de una gobernanza imperial, asegurada y asumida por Estados Unidos. Al mismo tiempo que estamos en camino hacia una sociedad-mundo, estamos en camino de que esta sociedad-mundo tome la forma de un Imperio-Mundo. Es verdad que este imperio-mundo apenas podría integrar a China, pero podría incorporar como satélites a Europa y Rusia. También es verdad que el carácter democrático y poliétnico de Estados Unidos impediría un Imperio racial y totalitario. Pero no impediría una dominación brutal y despiadada sobre las disconformidades y las resistencias a los intereses hegemónicos... La superación de la situación necesitaría una metamorfosis del todo inconcebible... que no es imposible, pero sí, es improbable (Morin, 2003e, p. 9).

Una de las dificultades que enfrenta el cambio de una figura societal se encuentra en el escaso desarrollo de las posibilidades de nuestro espíritu, nos encontramos como dice Morin en "la prehistoria del espíritu humano". La racionalidad científica clásica, para Morin la ciencia moderna, tiene la característica de impedirnos pensar de manera compleja, es decir global, relacional. Por tanto, necesitamos de un pensamiento complejo capaz de comprender la hipercomplejidad que nos constituye como condición de posibilidad para superar nuestra barbarie civilizada.

Aquí ya hay una reconstrucción total de lo que podría ser lo humano. Lo humano: el homo es sin duda sapiens, -quien lo va a dudar-. Pero, simultáneamente es demens. El homo sapiensdemens podrá acabar consciente o inconscientemente consigo mismo y con las posibilidades de vida en su planeta, pero podrá, también, sobrevivir de otra manera: creando una sociedadmundo, una sociedad civilizada. 


\section{d) La metamorfosis societal}

A estas alturas Morin nos aporta una cuarta metáfora para comprender la hipercomplejidad humana que somos y nos constituye. Se trata de la metáfora de la metamorfosis de la humanidad en la era planetaria:

Para entender qué es una metamorfosis, pensemos en aquello que transforma la oruga en libélula (mariposa). La oruga se ha encerrado en la crisálida. De pronto sus fagocitos encargados de defenderla de las agresiones externas atacan su propio organismo. Destruyen sus órganos incluyendo su aparato digestivo, puesto que la libélula cambiará de alimento. El único que se salva es el sistema nervioso que mantiene la identidad de ser y controla su metamorfosis. El resto del organismo queda destrozado. Y en esta destrucción sin piedad, se opera la construcción de un ser totalmente nuevo, y sin embargo totalmente igual. En esta agonía se opera una muerte-renacimiento. El ser nuevo que se ha formado querrá romper su crisálida, que de protección ha pasado a prisión. Con terribles esfuerzos convulsivos intentará, en muchas ocasiones, salir, y poco a poco, con dificultad, se liberará de ella. Sus alas estarán ajadas, pesadas, pegadas al cuerpo: no se podrán despegar inmediatamente. Habrá un largo tiempo de una inmovilidad casi petrificada, repentinamente cuando nadie podría anunciarlo, la libélula (mariposa) emprenderá el vuelo (Morin, 1998, pp. 182-183) ${ }^{8}$.

Fíjense en algo particular: Morin ya no hace uso de un lenguaje mecanicista (nave, mono o bimotor), ni de un lenguaje fenomenológico (sociedad-mundo), sino de un lenguaje biológico. ¿Por qué este cambio de lenguaje?, ¿qué tiene que ver el lenguaje con la racionalidad?, ¿con la nueva figura de la humanidad en la era planetaria?

Morin está pensado con las herramientas y lenguajes que le ofrece la revolución contemporánea del saber (Delgado \& Sotolongo, 2006), que tuvo entre otras cosas, que aprender de la hibridación de los lenguajes especializados. Y está pensando, sin lugar a dudas, en los aportes que tuvo su pensamiento desde los planteamientos desarrollados por el físico Mogorot Maruyama, quien demuestra que cuando una propiedad emergente se aplica a sistemas complejos o máquinas vivientes, estos sistemas pueden o bien degenerarse y morir, o bien regenerarse y sobrevivir en una nueva manera de ser capaz de enfrenar sus problemas vitales (Maruyama, 1961, pp. 45-60; 1963, pp. 78-92; 1974, pp. 136-280; 1992, pp. 301-307). El ejemplo de la metamorfosis de la mariposa es evidente.

Ahora bien, zen el ser humano la situación es la misma? Sí y no. Sí en cuanto que los seres humanos se constituyen en y por procesos de auto-eco-organización. No en cuanto que los

8. Sobre la reiterara utilización de las mariposas en el pensamiento moriniano (véase: Morin, 2010b; 2005). 
seres humanos, al mismo tiempo que se auto-eco-organizan se auto-eco-re-organizan de una manera propia: bio-culturalmente. Es decir que para poderse re-generar los humanos necesitamos no sólo de estrategias biológicas, sino también y al mismo tiempo de estrategias noológicas y socio-culturales (Morin, 1992). Los humanos somos seres bio-culturales, que en las condiciones actuales nos encontramos inmersos en un profundo proceso de transformación. Por ello, nos dice Morin:

La humanidad dejó de ser una noción meramente biológica debiendo ser plenamente reconocida con su inclusión indisociable en la biósfera; la humanidad dejó de ser una noción sin raíces, ella se enraizó en una "patria": la tierra, y la tierra es una patria en peligro; La humanidad dejó de ser una noción abstracta: es una realidad vital ya que desde ahora se encuentra en peligro de muerte, por primera vez. La humanidad ha dejado de ser una noción simplemente ideal y se ha vuelto una comunidad de destino y sólo la conciencia de esta comunidad le puede conducir a una comunidad de vida; la humanidad de ahora en adelante, es una noción ética: ella es lo que debe ser realizado por todos y cada uno. Mientras la especie humana continúa su aventura bajo la amenaza de autodestrucción, el imperativo es salvar la humanidad realizándola (Morin, 2003d, pp. 120-121).

Aquí hay una reestructuración total del término humanidad y humanismo. El término humanidad surge en Grecia para decir que los únicos humanos son los griegos, y todo no griego, es un bárbaro. O sea que el término humanidad, etimológicamente hablando, es la descalificación de todo no-griego en tanto que es no-humano. Luego con la llustración aparece el Humanismo, ya no humanidad sino humanismo-, y iqué es el Humanismo? Es la reestructuración del pensar a partir de las categorías griegas que habían sido deshechas en el mundo medieval. Es decir, es un volver al mundo categorial griego para entronizar nuevamente a la humanidad en contra de lo que no es ella: en este caso en contra de la deidad cristiana (de la Cristiandad). En el fondo, tanto en los griegos como en los modernos, la humanidad sigue siendo una abstracción.

Pero en los tiempos actuales, "la humanidad ha dejado de ser una noción simplemente ideal y se ha vuelto una comunidad de destino". La humanidad hoy no es un vocablo para diferenciar a los humanos de aquello que no lo son, sino una noción ética que pone en consideración a los humanos que se han convertido, por primera vez, en una "comunidad de destino". Es decir, en tanto que posibilidad de degenerarse o regenerarse en una organización cualitativamente distinta. Dicho en lenguaje político la humanidad es lo que ella puede hacer de sí misma: "ello es lo que debe ser realizado por todos y cada uno" de donde surge un nuevo imperativo moral: "mientras la especie humana continúa su aventura bajo la amenaza de autodestrucción, el imperativo es salvar la humanidad realizándola".

El caso de Roma es muy significativo. Ante una crisis histórica fundamental, Roma tenía las posibilidades para regenerase en otra organización socio-cultural, pero también tenía las posibi- 
lidades de su aniquilamiento. Roma eligió la segunda posibilidad y se perdió como imperio: escogió la degeneración de sus posibilidades y no la regeneración de las mismas. Nosotros estamos hoy en una nueva situación, pero también estamos expuestas a utilizar todas nuestras estrategias posibilitantes. Y estas posibilidades sólo podrán realizarse verdaderamente con el concurso y la ayuda de la racionalidad humana, con la conciencia humana y la regeneración ético-política.

Esto significa que en el mundo animal las metamorfosis posibles son producto de los procesos inconscientes; las metamorfosis de las sociedades agrarias a las sociales históricas, fueron productos de procesos en gran medida inconscientes; nuestra mutación actual, -posible, pero improbable-, por diferenciación con las anteriores metamorfosis, será en parte involuntaria, pero no se podrá dar, sin nuestra intervención conciente. La humanidad como un todo vital no tiene programa previo de su transformación, ni tiene un sistema nervioso que la gobierne, su "naturaleza" consiste en no tener naturaleza, por ello su destino será una construcción a partir de lo que ella misma sueña de sí misma, y no una concatenación biológica prevista de antemano.

Los distintos países del globo se han transformado de alguna manera, y quizás occidente ha podido elaborar una suerte de sistema nervioso simpático, pero el sistema cerebral, sin embargo, no se ha podido constituir. Seguimos, por el momento, en "la prehistoria del espíritu humano", en la imposibilidad de comprendernos desde nuestra más profunda hipercomplejidad, de percibir nuestra más profunda simbiosis con la naturaleza de la cual hacemos parte y dependemos; seguimos siendo arrogantes -antropocéntricos, occidentalocéntricos en el sentido duro y fuerte del término-, y el esfuerzo decisivo está por hacer.

A diferencia del insecto, Europa no tiene programa previo de su transformación, no tiene un sistema nervioso que la gobierne... todos los países europeos se han transformado de alguna manera y los de occidente han podido elaborar una suerte de sistema nervioso simpático. Pero, el sistema cerebral, sin embargo, no se ha podido constituir. La metamorfosis está inacabada, no somos ni oruga, ni libélula, estamos aún dentro de la crisálida. El esfuerzo decisivo está por hacer. La metamorfosis puede abortar, pero sigue su curso. La sabiduría consistirá en contribuir a ello (Morin, 2003d, p. 183).

La sabiduría será entonces la complejificación de nuestros saberes complejos para hacerlos llegar hasta la hipercomplejidad humana que somos y nos constituye; será una nueva racionalidad que operando desde el paradigma simplificador, reductor y disyuntor de la ciencia clásica, nos posibilite la emergencia de la humanidad en la era planetaria. La metamorfosis cognitiva está por hacer, mientras tanto, los humanos que vivimos en este siglo XXI continuamos en la edad de hierro planetaria (Morin, 2003d, p. 183).

En síntesis, la emergencia de la humanidad como comunidad de destino planetario, no se dará sin una concomitante reforma del pensamiento (Morin, 2001). Las formas de pensamiento que 
actualmente tenemos para comprendernos en el mundo científico son profundamente ciegas, tan ciegas que no acaban de comprender que lo que está en sus manos es el destino de nuestra propia sostenibilidad, y eso a nivel planetario (Beck, 2006). La escisión entre la cultura humanística y la cultura científica es nefasta tanto para la una como para la otra, y para ambas a un mismo tiempo; las ciencias "duras" no tienen como referente al hombre y las ciencias humanas lo han despedazado en fragmentos para poderlo conocer. Los antropólogos hablan de la cultura, los etnólogos hablan del comportamiento, los historiadores hablan de las acciones, los psicólogos de la psique, los filósofos hablan del pensamiento: cada uno habla de una parte del hombre, ninguno habla del hombre total, ninguno capta la hipercomplejidad que nos constituye, y el hombre termina pulverizado en una racionalidad ciega (Morin, 1984, pp. 293-368). Por ello, se hace necesaria una reorganización conceptual del pensamiento: no hay otra posibilidad.

Por ello tenemos que comprender que la revolución se juega hoy no tanto en el terreno e las ideas buenas o verdaderas opuestas en una lucha de vida o muerte a las ideas malas y falsas, sino en el terreno de la complejidad del modo de organización de las ideas. La salida de la 'edad de hierro planetaria' y de "la prehistoria del espíritu' nos exige pensar de forma radicalmente compleja (Morin, 1992, p. 244). Es por lo que pienso que el problema crucial es el del principio organizador del conocimiento, y que lo que es vital hoy, no es solamente aprender, no solamente reaprender, no solamente desaprender, sino reorganizar nuestro sistema mental para reaprender a aprender (Morin, 1983, p. 35).

\section{LA EMERGENCIA DE LA ANTROPOLÍTICA}

A Morin se le reconoce poco o casi nada como un pensador de lo político, y curiosamente, es un gran pensador político. Por ello, en esta última parte me gustaría reivindicar dos aspectos de su pensamiento: el carácter de teoría crítica de la sociedad y el carácter de pensamiento político.

En el fondo, y esta es mi hipótesis de lectura, la propuesta moriniana es una teoría crítica de la sociedad (Osorio, 2009a, pp. 145-173). Si leemos a Morin desde esta perspectiva ustedes comprenderán el propósito de nuestra Cátedra: se trata de poner en relación la trasformación de la humanidad en la era planetaria con el abordaje político de la misma. En palabras de Morin, con la emergencia de una antropolítica (Morin \& Kern, 1993, pp. 167-187) y de una política de civilización (Morin, 2009b).

En otro de sus textos, analizando la situación de los mundos socio-culturales de la sociedad europea, nos dice el pensador:

El mundo está en noche y niebla, noche y niebla que también cubren a Europa. El discurso-catástrofe y el discurso-euforia son igualmente vanos. Antes de hacer planes y retra-planes, tenemos que insertar en nuestro pensamiento la incertidumbre, unir 
riesgos y posibilidades en nuestro espíritu, apostar por la vida y contra la nada. En medio de la incertidumbre tenemos, al menos la certidumbre, de que una nueva metamorfosis en Europa ha comenzado (Morin, 1998, pp. 182-183).

Estamos en noche y niebla ${ }^{9}$. Dicho de otra manera durísima, estamos en la época en que nos acribillamos miserablemente unos con otros, sin encontrar aún solución a nuestros problemas y de seguir así, el Planeta Tierra continuará su marcha y para bien o para mal, muy probablemente sin nuestra presencia.

Pensar la continuidad de la humanidad como comunidad de destino planetario será el motivo de una antropolítica y de una política de civilización. Dos grandes objetivos que se harán a contra marcha de dos grandes dificultades: una, la exaltación de lo propio en detrimento de lo distinto, lógica afirmativa de la modernidad que ha devenido en el totalitarismo político, y dos: la despolitización de la dimensión política en la vida social y cotidiana, situación que nos ha llevado a la pérdida del bios político en la democracia occidental (Osorio, 2009b, pp. 147-166).

Con el término despolitización de la dimensión política se refiere Morin a la deglución de la política por la economía. En efecto, la política en lugar de pensar los problemas globales que sufre la humanidad, los problemas que hemos de asumir como comunidad de destino planetario, sólo piensa en términos de mercado. Y el pensamiento que tenemos para pensar al ser humano está tan fragmentado, está tan dividido, está tan atomizado, que no hay forma de pensar la política desde la complejidad humana que nos constituye. La política de los politólogos, es decir la política de los especialistas que sólo conocen fragmentos, se convierte en política bárbara que deja de lado lo único serio que hay que pensar: la complejidad, las complejidades humanas, los problemas fundamentales.

Pensar los grandes problemas de la humanidad como condición de posibilidad de vida humana y no-humana en la era planetaria es ya, para Morin, estar en otra posibilidad política, ya no en una política de los poderes para sacrificar a los que no son de su grupo político, sino que un una antropolítica para la salvar a la humanidad realizándola. Y para esto no hay programa, tan sólo hay estrategias. Las estrategias a diferencia de los programas no son teleológicos en un principio, sino tan sólo maneras de asumir las dificultades que se presentan en cada caso, tratando de salvar lo que es genérico en la humanidad. ¿Que es lo genérico en la humanidad? Lo genérico para Morin, es la capacidad histórica que tiene el género humano de sobreponerse ante las amenazas de muerte, al estilo de las células totipotenciales que se transforman en las células que necesita el organismo para sobrevivir; lo genérico es la capacidad de solucionar los problemas

9. Noche y niebla en alemán, se decía en los campos de concentración como santo y seña para explicitar a la persona que había sido designada para morir en una cámara de gas o iba a ser fusilada. 
históricos con los que vive, de cara a una nueva organización, ella sí, capaz de solucionar dichos problemas.

Esto fue, según Morin, lo que pensó Marx de la racionalidad científica en su tiempo: una capacidad que generaría vida, aunque desafortunadamente al no tener una comprensión compleja de racionalidad, -Marx es hijo de su tiempo-, la estrategia científica se convirtió en su contrario. Stalin le da la razón a Morin, las pretensiones de la acción siempre pueden pervertirse, siempre pueden desviarse, siempre pueden volverse contra sus propias intencionalidades. Por eso Morin dirá, la única política que podríamos hacer, la única vía posible que no termine en su contrario será una antropolítica que se auto-genere como una ecología de la acción, como una ética de la comprensión (Morin, 2006).

Concebir la Humana Conditio como una emergencia planetaria requiere de una nueva manera de pensar, requiere de un pensamiento complejo capaz de pensar transformación ético-política de la humanidad en la era planetaria. Dicho de otra manera, la antropolítica es la manera cómo podemos pensar complejamente la emergencia de la humanidad que se ha vuelto planetaria y para la cual no tenemos conceptos, ni categorías, ni lógicas porque ni la filosofía política, ni la economía política, ni las ciencias sociales del siglo XIX nos permiten comprender esta emergencia. Entonces, la antropolítica tiene que ver con una nueva manera de pensar la humanidad (Humana Conditio) en la era planetaria.

Adicionalmente a las dos dificultades para pensar lo político desde el ámbito de la complejidad planetaria (la afirmación de sí en la negación de lo otro, y la despolitización de la política), contamos según Morin, con otras dificultades políticas de gran envergadura para lograr transformación (metamorfosis) requerida:

a) La falta de instituciones mundiales para poder pensar complejamente la planetarización. Seguimos pensándonos como se pensaron los hombres del siglo XVIII, como estadosnación, como estados nacionales, y desde allí es imposible pensar los desafíos planetarios. El concepto de estado-nación es un concepto políticamente errado para pensar la comunidad de destino planetario, porque si afirmamos la posibilidad del estado-nación como afirmación de la identidad etnográfica, no nos queda más salida que la afirmación de lo propio en la negación de lo diferente: etnocentrismos y totalitarismos contemporáneos.

b) La falta de conciencia ante un destino común. Todavía no caemos en cuenta que si se hunde esta nave, los humanos nos hundimos todos como comunidad de destino planetario. Es un hecho, como lo muestra la astrofísica actual, que existen otros soles, otras galaxias, otros planetas, y que posiblemente en ellos, -como en este minúsculo planeta-, se pueda dar la emergencia de la vida, pero mientras tanto sólo tenemos este planeta para poder 
vivir juntos: para civilizarnos y sobrevivir. Entonces podríamos dar un voto de confianza a una nueva racionalidad que posibilite el surgimiento de una nueva forma de gobernabilidad planetaria. Pensar en una nueva forma de gobernabilidad planetaria es lo que Morin va a llamar política de civilización. Es decir, una política que comprenda la hipercomplejidad humana en su proceso de planetarización, y al mismo tiempo, una antropolítica, es decir, una forma de pensar la humanidad como comunidad de destino planetario para salvar la humanidad realizándola.

Para finalizar, me gustaría decir que la complejidad, y más exactamente el pensamiento complejo de Edgar Morin, -dicho en clave antropolítica-, nos sirve para pensar el tema clásico de la filosofía política desde el profesor Aristóteles hasta nuestros días: la condición humana. Este tema se volvió a introducir en los debates contemporáneos de la mano de una mujer extraordinariamente brillante, la filósofa alemana de origen judío Hannah Arendt (1993). Morin vuelve a Arendt para pensar la condición humana en la era planetaria y al mejor estilo de la tradición medieval, prefiere decirlo en latín: la Humana Conditio. La complejidad es, pues, una metáfora para pensar la Humana Conditio en la era planetaria.

\section{BIBLIOGRAFÍA}

- $\quad$ Arendt, Hannah. (1993). La condición humana. En: Ramón Gil (Trad.). Barcelona: Editorial Paidós.

- Baudrillard, Jean. (2003). La violencia de lo mundial. La violencia del mundo, Buenos Aires: Libros del Zorzal.

- $\quad$ Beck, Ulrich. (2006). La sociedad del riesgo. En busca de la seguridad perdida. Barcelona: Editorial Paidós.

- Corbí, Marià. (1992). La sociedad en la segunda revolución industrial. Proyectar la sociedad-reconvertir la religión. Los nuevos ciudadanos, (pp. 17-100). Barcelona: Editorial Herder.

- Delgado Díaz, Carlos Jesús \& Sotolongo Codina, Pedro Luis. (2006). La revolución contemporánea del saber y la complejidad social: Hacia unas ciencias sociales de nuevo tipo. Recuperado de http://bibliotecavirtual.clacso.org.ar/ar/libros/campus/soto/soto.html

- Habermas, Jürgen. (1987a). La crítica de la razón instrumental. Teoría de la acción comunicativa. Tomo l: Racionalidad de la acción y racionalización social, (pp. 365-508). Madrid: Taurus Ediciones. 
- Habermas, Jürgen. (1987b). Tareas de una Teoría crítica de la sociedad. Teoría de la acción comunicativa. Tomo II: Crítica de la razón funcionalista, (pp. 527-572). Madrid: Taurus Ediciones.

- Habermas, Jürgen. (1989). El contenido normativo de la modernidad. El discurso filosófico de la modernidad, (pp. 397-433). Madrid: Taurus Ediciones.

- Heidegger, Martin. (1994). Construir, habitar, pensar. Conferencias y artículos, (pp. 127142). Barcelona: Ediciones del Serbal.

- Heidegger, Martin. (2003). Confrontación del análisis de la mundaneidad con la interpretación del mundo en Descartes. Ser y tiempo, (pp. 115-127). Madrid: Editorial Trotta.

- Maruyama, M. (1961). Communicational epistemology. British Journal for the Philosophy of Science, XI(44), 4560.

- Maruyama, M. (1963). Basic elements in Misunderstarding I. Dialéctica, (17), 78-92.

- Maruyama, M. (1974). Paradigmatology and its application to cross disciplinary, crossprofessional and cross-cultural communications. Cybernética, XVII(2), 136-280.

- Maruyama, M. (1992). Disfunctional, misfunctional and tocsifunctional aspects of cultures. Technological Forecasting and Social Change, (42), 301-307.

- Morin, Edgar. (1974). La hominización. El paradigma perdido. Ensayo de bioantropología, (pp. 15-109). Barcelona: Editorial Kairós.

- Morin, Edgar. (1982). Para salir del siglo XX. Barcelona: Editorial Kairós.

- Morin, Edgar. (1983). El método I: La naturaleza de la naturaleza, Madrid: Ediciones Cátedra.

- Morin, Edgar. (1984). Por el pensamiento complejo. Ciencia con conciencia, (pp. 293368). Barcelona: Editorial Anthropos.

- Morin, Edgar. (1992). El Método IV: Las ideas. Su hábitat, su vida, sus costumbres, su organización. Madrid: Ediciones Cátedra.

- Morin Edgar \& Kern Anne Brigitte. (1993). Tierra patria. Barcelona: Editorial Kairós. 
- Morin Edgar. (1996). Las reorganizaciones genéticas. Mis demonios, (pp. 202-217). Barcelona: Editorial Kairós.

- Morin Edgar. (1997). La necesidad de un pensamiento complejo. En: Sergio González Moena, (Comp.) Pensamiento complejo. En torno a Edgar Morin, América Latina y los procesos educativos, (pp. 13-22). Bogotá: Editorial Magisterio.

- Morin, Edgar. (1998). Pensar Europa. Barcelona: Editorial Gedisa.

- Morin, Edgar. (2001). La cabeza bien puesta. Repensar la reforma-reformar el pensamiento. Buenos Aires: Ediciones Nueva Visión.

- Morin, Edgar, Ciurana Roger, Emilio \& Domingo Motta, Raúl. (2003a). Los desafíos de la era planetaria: el posible despertar de la sociedad-mundo. Educar en la era planetaria. Barcelona: Editorial Gedisa.

- Morin, Edgar. (2003b). En el corazón de la crisis planetaria. La violencia del mundo, (pp. 35-54). Buenos Aires: Libros del Zorzal.

- Morin, Edgar. (2003c). La humanidad de la humanidad. La identidad humana. Madrid: Ediciones Cátedra.

- Morin, Edgar. (2003d). Los siete saberes necesarios para la educación del futuro. Bogotá: Magisterio.

- Morin, Edgar. (2003e). ¿Sociedad mundo o imperio mundo? Más allá de la globalización y el desarrollo. Gazeta de Antropología 19. Recuperado Junio 5, 2008 de www.pensamientocomplejo.com.ar/biblio.asp.

- Morin Edgar. (2005, Otoño). Esperando nuestra mariposa. Revista Iniciativa Socialista, 77, Recuperado de http://www.inisoc.org/i77morin.htm.

- Morin, Edgar. (2006). El Método VI: Ética. Madrid: Ediciones Cátedra.

- Morin, Edgar. (2008). Estamos en un Titanic. Recuperado de www.revistafuturos.info/ raw_text/raw.../titanic_morin.pdf

- Morin, Edgar. (2009a). Breve historia de la barbarie en occidente. Barcelona: Editorial Kairós.

- Morin, Edgar. (2009b). Para una política de civilización. Barcelona: Editorial Paidós. 
- Morin Edgar. (2010a). Complejidad restringida, complejidad general. Revista estudios, VIII(93), 81-135.

- Morin Edgar. (2010b). Elogio de la metamorfosis. Recuperado de http://www.elpais.com/ articulo/opinion/Elogio/metamorfosis/elpepuopi/20100117elpepiopi_13/Tes

- Morin Edgar. (2011, 9 de Enero). Las noches están preñadas y nadie conoce el día que nacerán. Recuperado de http://www.ipcem.net/documentos/articulo-morin.pdf.

- Osorio García Sergio Néstor. (2009a). De la "Teoría crítica de la sociedad" a la "paradigmatología" de Edgar Morin. En: Maldonado Castañeda, Carlos Eduardo (Ed.). Complejidad: revolución científica y teoría, (pp. 145-173). Bogotá: Universidad del Rosario, Colección complejidad.

- Osorio García, Sergio Néstor. (2009b). Homo Politicus. Criterios básicos para discernir la política y lo político en tiempos de globalización. Revista de Relaciones Internacionales, Estrategia y Seguridad. Bogotá: UMNG, 4(2), 147-166

- Scherer, René. (1975). El último de los filósofos. Heidegger, (pp.11-60). Madrid: Ediciones EDAF.

- Solana Ruíz, José Luis. (2001). Epistemología de la complejidad y teoría de la organización. Antropología y complejidad humana. La antropología compleja de Edgar Morin, (pp. 165-304). Granada: Editorial Comares. 